\title{
Cardiac CT provides uniquely accurate and comprehensive assessment of bioprosthetic aortic valve stenosis
}

\author{
Jamal N Khan, ${ }^{1}$ Brian Devlin, ${ }^{2}$ Satya Verma, ${ }^{1}$ Balazs Ruzsics ${ }^{1}$
}

'Department of Cardiology, Royal Liverpool and Broadgreen University Hospitals NHS Trust, Liverpool, UK

${ }^{2}$ Department of Radiology, Royal Liverpool and Broadgreen University Hospitals NHS Trust, Liverpool, UK

Correspondence to Dr Jamal N Khan, jamal.khan@rlbuht.nhs.uk

Accepted 19 April 2018
Check for updates

To cite: Khan JN, Devlin B, Verma S, et al. BMJ Case Rep Published Online First: [please include Day Month Year]. doi:10.1136/bcr-2018225045

\section{DESCRIPTION}

An 81-year-old man was referred to the cardiology clinic with breathlessness and angina. His history included triple-vessel coronary artery bypass graft (CABG) plus St Jude Epic $21 \mathrm{~mm}$ bioprosthetic aortic valve replacement (AVR) surgery 7 years prior.

Transthoracic echocardiography (TTE) demonstrated severely elevated Doppler AVR velocities (VMax $4.7 \mathrm{~m} / \mathrm{s}$ ) and severe AVR stenosis (valve area $\left.0.7 \mathrm{~cm}^{2}\right)$. This was the suspected cause of symptoms, and transfemoral valve-in-valve AVR valve-in-valve transcatheter aortic valve implantation (VIV-TAVI) was being considered. However, TTE image quality was suboptimal due to echocardiographic windows and valve echogenicity, precluding accurate leaflet assessment (figure 1A-D). Transoesophageal echocardiography corroborated TTE findings (VMax 5.5 $\mathrm{m} / \mathrm{s}$ ) but failed to delineate the mechanism of AVR restriction (figure 1E-H). Degenerative leaflet calcification was evident on echocardiography, however echogenicity around the sewing ring prevented distinction between calcification and pannus, and ultrasound dropout precluded thrombus exclusion.

Invasive coronary angiography confirmed severe native coronary disease and patency of two bypass grafts, however the third graft could not be cannulated. Cardiovascular MRI confirmed inferolateral infarction, mild left ventricular systolic dysfunction and significant AVR stenosis. However, high antegrade AVR flow velocities and metallic valve stents resulted in signal loss and failure to delineate the mechanism of AVR restriction due to flow and susceptibility artefacts, respectively.

Given the limitations of echocardiography and angiography, a prospectively gated cardiac CT scan was performed (figure 2A,B). Its high spatial resolution and ability to characterise tissue based on CT absorption (attenuation) characteristics allowed accurate non-invasive AVR and coronary artery assessment. Absence of lung parenchyma and pulmonary embolic disease, and excellent patency of all bypass grafts were confirmed. Circumferential low attenuation (125 Hounsfield units; HU) around the underside of the sewing ring was consistent with pannus. There was accumulation of a large area of very low attenuation material (35 HU) over the non-coronary cusp and adjacent sewing ring segment. This was in keeping with significant thrombus burden causing symptoms due to leaflet restriction and orifice encroachment.

VIV-TAVI workup was postponed, and a repeat CT study after 3 months of warfarinisation confirmed thrombus resolution. Residual thin circumferential pannus and mild non-calcified degenerative leaflet thickening were confirmed (figure 2C,D). The patient was rendered asymptomatic with, corroboratively, significantly reduced TTE AVR velocities (VMax $3.8 \mathrm{~m} / \mathrm{s}$ ).

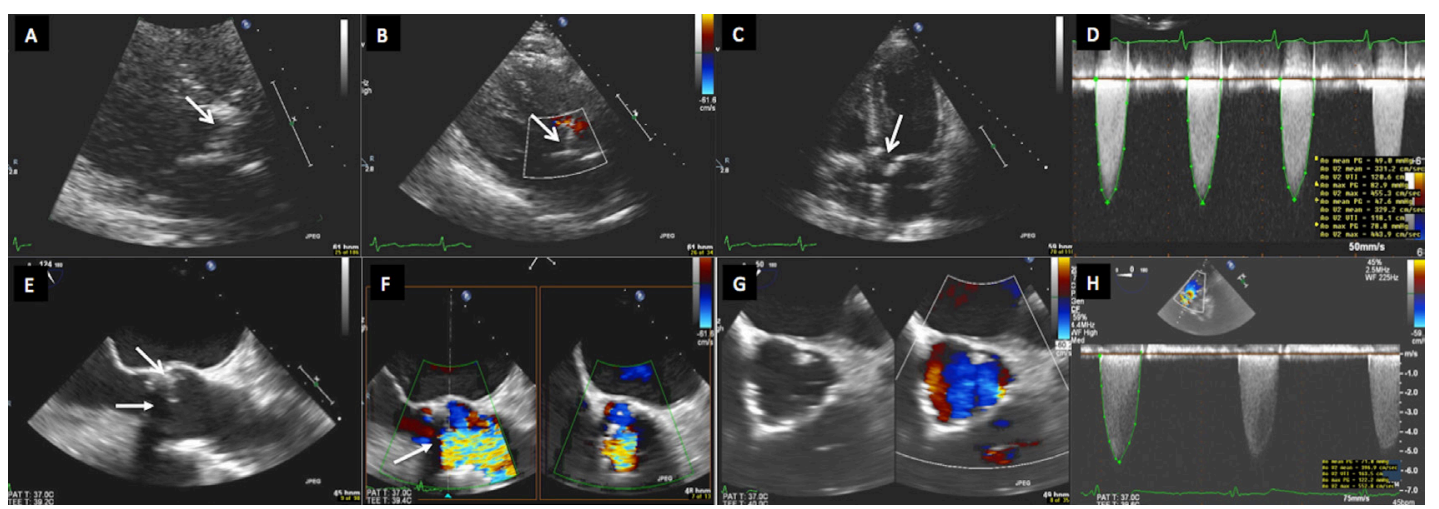

Figure 1 Top row (transthoracic echocardiography): (A) Parasternal long-axis view with limited AVR visualisation (open-headed arrow) with increased echogenicity which can be due to pannus, calcification or metallic valve components; (B) turbulent antegrade colour-Doppler flow; (C) apical five-chamber view with limited AVR visualisation (open-headed arrow); (D) severely elevated antegrade AVR velocities on continuous-wave Doppler (VMax $4.6 \mathrm{~m} / \mathrm{s}$ ) suggestive of severe valve stenosis/obstruction. Bottom row (transoesophageal echocardiography): (E-G) Limited AVR visualisation (open-headed arrow) with dropout signal loss artefact (closed-headed arrow) precluding optimal valve leaflet visualisation; $(H)$ severely elevated antegrade AVR velocities (VMax $5.5 \mathrm{~m} / \mathrm{s}$ ). AVR, aortic valve replacement. 


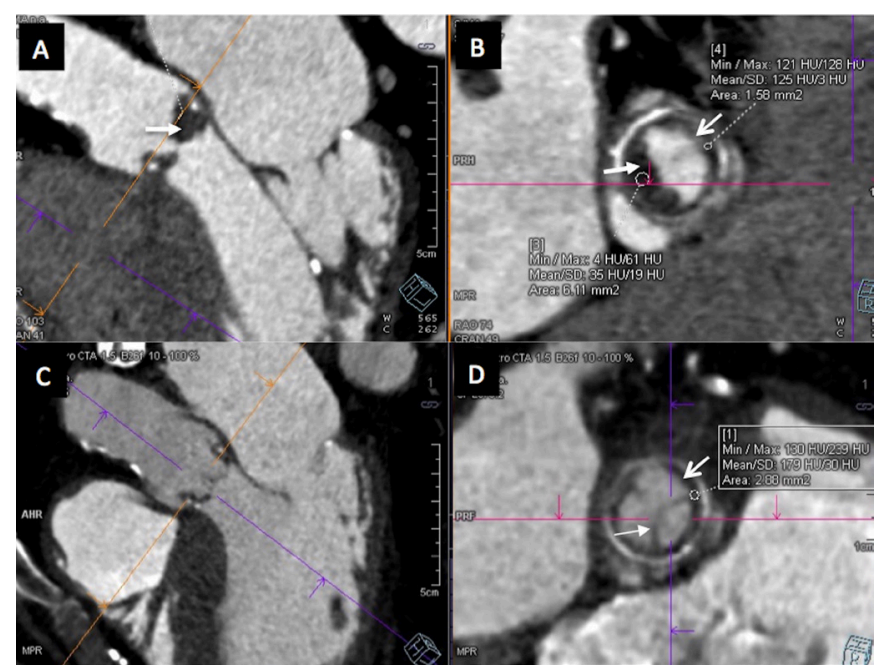

Figure 2 (Cardiac CT): orthogonal long-axis ( $A$ and $C$ ) and short-axis $(B$ and $D)$ views of bileaflet mechanical aortic valve replacement in closed position. ( $A$ and $B ; C T$ scan 1 ): accumulation of large burden of very low attenuation ( $35 \mathrm{HU}$ ) material over non coronary cusp (NCC) and adjacent portion of sewing ring (thrombus) and circumferential rim of low attenuation material on the inside of underside of sewing ring (125 HU, pannus); (C and D; CT scan 2): complete resolution of thrombus with residual mild pannus burden after 3 months of warfarinisation, closed leaflets visible (thin arrow). HU, Hounsfield unit.

Cardiac CT was the only modality accurately assessing the AVR, allowing appropriate therapy to be directed and preventing redo AVR surgery. Mild residual asymptomatic AVR stenosis due to mild leaflet degeneration and pannus was confirmed. The patient remains asymptomatic 6 months later on warfarin.

Prosthetic valve imaging using echocardiography can be limited by reverberation (reflective) and shielding (signal loss) artefacts from metal components which can also be challenging to differentiate from degenerative calcification. ${ }^{12} \mathrm{X}$-ray fluoroscopy can demonstrate leaflet mobility but is limited by its angle dependence and inability to visualise pannus and thrombus. Cardiac CT allows excellent non-invasive prosthetic valve assessment due to excellent spatial resolution and visualisation of leaflet motion. ${ }^{12}$ CT attenuation characteristics (HU) allow distinction between the key differentials of valve obstruction-thrombus and pannus-which can be notoriously challenging using echocardiography, X-ray fluoroscopy and cardiovascular MRI. ${ }^{1-3}$ CT also provides simultaneous excellent native coronary artery, CABG, aorta and pulmonary arterial imaging. Accurate CT aortic root assessment allows unrivalled assessment of endocarditic complications, including dehiscence, abscess, fistula and aneurysm formation. Cardiac CT is a valuable but currently underused tool in the multimodality imaging assessment of prosthetic cardiac valves, despite widespread availability.

\section{Patient's perspective}

'The CT scan helped the doctors work out why I was getting short of breath and treat me without me having to have another operation.'

\section{Learning points}

- Imaging of prosthetic cardiac valves using echocardiography can be significantly limited by reverberation and shielding artefacts, degrading leaflet assessment.

- Degenerative calcification, pannus and thrombus are key differentials for bioprosthetic valve obstruction and can be challenging to assess on echocardiography, X-ray fluoroscopy and cardiovascular MRI.

- Cardiac CT allows accurate non-invasive assessment of prosthetic valves with high spatial resolution. It allows excellent assessment of leaflet mobility, assessment for calcification, pannus and thrombus, visualisation of complications arising from endocarditis (abscesses, dehiscence) and also permits left ventricular and coronary artery assessment within the same study.

Contributors All authors were heavily involved in production of the manuscript and images, and then finalising approval of the version published. All authors are agreeable to be accountable for the article and to ensure that all questions regarding the accuracy or integrity of the article are investigated and resolved. JNK: planning, conception and production of manuscript/images; clinical management of patient; undertook cardiac imaging (TTE, TOE, CMR, CT) and interpretation of data. BD: review and editing of manuscript; involved in cardiac imaging (CT) and interpretation of data. SV: review and editing of manuscript; clinical management of patient; involved in cardiac imaging (echo) and interpretation of data. BR: review and editing of manuscript; clinical management of patient; involved in cardiac imaging (CMR, CT) and interpretation of data.

Funding The authors have not declared a specific grant for this research from any funding agency in the public, commercial or not-for-profit sectors.

Competing interests None declared.

Patient consent Obtained.

Provenance and peer review Not commissioned; externally peer reviewed.

(C) BMJ Publishing Group Ltd (unless otherwise stated in the text of the article) 2018. All rights reserved. No commercial use is permitted unless otherwise expressly granted.

\section{REFERENCES}

1 Moss AJ, Dweck MR, Dreisbach JG, et al. Complementary role of cardiac CT in the assessment of aortic valve replacement dysfunction. Open Heart 2016;3:e000494.

2 Tsai WL, Tsai IC, Chen MC, et al. Comprehensive evaluation of patients with suspected prosthetic heart valve disorders using MDCT. AJR Am J Roentgenol 2011;196:353-60.

3 Tanis W, Habets J, van den Brink RB, et al. Differentiation of thrombus from pannus as the cause of acquired mechanical prosthetic heart valve obstruction by non-invasive imaging: a review of the literature. Eur Heart J Cardiovasc Imaging 2014;15:119-29. 
Copyright 2018 BMJ Publishing Group. All rights reserved. For permission to reuse any of this content visit http://group.bmj.com/group/rights-licensing/permissions.

BMJ Case Report Fellows may re-use this article for personal use and teaching without any further permission.

Become a Fellow of BMJ Case Reports today and you can:

- Submit as many cases as you like

- Enjoy fast sympathetic peer review and rapid publication of accepted articles

Access all the published articles

Re-use any of the published material for personal use and teaching without further permission

For information on Institutional Fellowships contact consortiasales@bmjgroup.com

Visit casereports.bmj.com for more articles like this and to become a Fellow 